\title{
Una necesidad imprescindible: Desterrar definitivamente el régimen de responsabilidad objetiva del infraccional aduanero(*)
}

\section{An essential need: Banishing permanently strict liability from the customs infringement procedures}

\author{
Andrés Varela ${ }^{(* *)}$ \\ Universidad de la República
}

\begin{abstract}
Resumen: El presente artículo aborda el estudio del régimen de responsabilidad objetiva que subsiste en materia infraccional aduanera, los fundamentos sostenidos para su existencia o pervivencia, y sus consecuencias. Asimismo, se desarrollan los argumentos contrarios a dicho régimen de imputación de la responsabilidad. Así, y partido de ello, se tratan de encontrar soluciones jurídicas que, sin vulneren los derechos de los administrados al juzgar las infracciones aduaneras, permitan resolver el fundamento de su sustitución, y ello, mediante un correcto establecimiento de presunciones legales relativas que permitan presumir la intención, cuando ella sea de difícil comprobación para el Fisco.
\end{abstract}

Palabras clave: Derecho Aduanero - Infraccional aduanero - lus Puniendi - Principio de culpabilidad - Responsabilidad objetiva - Presunciones - Bien Jurídico Tutelado - Código Aduanero de la República Oriental del Uruguay

\begin{abstract}
This paper analyzes the strict liability system surviving in customs infringement procedures, the grounds for its existence or survival and its consequences. Also, the arguments against such system of liability attribution
\end{abstract}

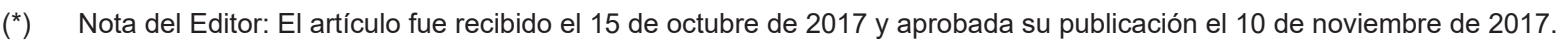

${ }^{* *}$ Doctor en Derecho y Ciencias Sociales, Facultad de Derecho, Universidad de la República (Uruguay). Docente encargado de los Cursos de Régimen Jurídico del Comercio Exterior: Derecho Aduanero, y Práctica del Comercio Exterior en la Facultad de Derecho, Universidad de la República (Uruguay). Docente encargado de los Cursos de "Actualización y Profundización en Derecho Aduanero", e "Introducción al Derecho Aduanero", en la Escuela de Posgrado, Facultad de Derecho, Universidad de la República (Uruguay). Coordinador General de la "Primera Jornada Académica de Derecho Aduanero", Paraninfo de la Universidad de la República (2014), "Segunda Jornada Académica de Derecho Aduanero", Paraninfo de la Universidad de la República (2015), "Tercera Jornada Académica de Derecho Aduanero", Asociación de Despachantes de Aduana (2016), y "Cuarta Jornada Académica de Derecho Aduanero", Asociación de Despachantes de Aduana (2017). Disertante en diversos eventos académicos sobre Derecho Aduanero. Miembro del Instituto Uruguayo de Derecho Aduanero, y del Instituto de Finanzas Públicas (Facultad de Derecho, Universidad de la República). Correo electrónico: drvarela@adinet.com.uy 


\section{Una necesidad imprescindible: Desterrar definitivamente el régimen de responsabilidad objetiva del infraccional aduanero An essential need: Banishing permanently strict liability from the customs infringement procedures}

are examined. Thus, from such starting point, through a precise enumeration of statutory rebuttable presumptions whose intention can be presumed whenever it is difficult for Tax Authorities to prove such presumptions, I intend to find legal solutions to determine the grounds for its replacement without affecting the rights of the relevant individuals or legal entities when the customs infringements are decided.

Keywords: Customs Law - Customs Infringement Procedure - lus Puniendi - Principle of culpability - Strict liability - PresumptionsLegally Protected Interest- Customs Code of the Republic of Uruguay

Sumario: 1. Introducción_2. Infracciones y sanciones aduaneras: su finalidad y la imputación de su responsabilidad_3. El régimen de responsabilidad objetiva_4. ¿Que protege el régimen de responsabilidad objetiva en las infracciones aduaneras? Las posibles causas alegadas para pretender la supervivencia del régimen_5. El caso de Uruguay: Grandes avances del CAROU, dificultades actuales, y otras batallas dogmáticas para dar y vencer_6. Las presunciones en materia de imputación: un medio para equilibrar la dificultad de probar al Fisco, y que le permite probar al eventual imputado_7. Conclusiones_8. Referencias bibliográficas.

\section{Introducción}

Uno de los debates de mayor actualidad en materia infraccional aduanera, que se replica en casi toda Latinoamérica(1), es (sin lugar a dudas) la pervivencia (o no) del régimen de responsabilidad objetiva en el infraccional aduanero.
A nuestro juicio, desde ya lo adelantamos, no existe ninguna razón jurídica (ni de otra naturaleza) que permita sostener el mantenimiento o pervivencia del régimen de responsabilidad objetiva en materia de represivo aduanero, al menos sin que ello no signifique el violentar principios de rango constitucional, así como de Derecho Sancionador. Adherimos a Soler, quien comparte con Izurieta y Sea, en el sentido que la objetividad de las infracciones tributarias (y que nosotros extendemos a las aduaneras), constituyen una rémora en el derecho represivo ${ }^{(2)}$ que repugna al sentido ético común de la población y a la filosofía que impregna la Constitución ${ }^{(3)(4)}$. En igual sentido, y entre nosotros, se ha expresado el jurista uruguayo Pablo Labandera ${ }^{(5)}$

En nuestro concepto, el Derecho Aduanero Sancionatorio (que comprende el ámbito de los Delitos y las Infracciones aduaneras) es una manifestación de la potestad punitiva del Estado. Por ello, y por su naturaleza, para la interpretación y aplicación de sus normas debe recurrirse a los métodos, principios y técnicas del Derecho Penal, por ser éste último el que mayores avances dogmáticos ha tenido dentro del Derecho Sancionador ${ }^{(6)}$. Pero además, por la necesidad de garantizar los derechos fundamentales del ciudadano (Nieto 2012 ,

(1) Si bien reconocemos que en algunos países como Argentina felizmente dicha discusión fue superada hace largo tiempo. Cónfer Enrique Barreira y Héctor Vidal Albarracin, La responsabilidad en las infracciones aduaneras (Argentina: La Ley, 1989), 925; Juan Bonzón, Derecho Infraccional Aduanero (Buenos Aires: Hammurabi, 1987), 76; Juan M. Sluman "Pensando la culpa en las Infracciones Aduaneras", en Estudios de Derecho Aduanero. Homenaje a los 30 años del Código Aduanero, coord. Juan Patricio Cotter (Buenos Aires: Editorial Lexis Nexis, 2011).

(2) Pese a que refiere al derecho represivo argentino, lo extendemos a toda Latinoamérica.

(3) Pese a que refiere a la Constitución de la Nación Argentina, lo extendemos a la Constitución de la República (Uruguay)

(4) Soler, Osvaldo H., Derechos y Defensas del Contribuyente frente al Fisco (Buenos Aires: La Ley, 2001), 79, quien cita a Izurrieta y Sea, Álvaro, "Las infracciones aduaneras y la objetividad”, en Rev. Impuestos, XLII-A, 481 y siguientes.

(5) En igual sentido Pablo Labandera, "La responsabilidad objetiva en materia de Derecho Aduanero: una rémora inaceptable", en Tribuna del Abogado 178, (junio-julio 2012): 19-22.

(6) Cónfer Nieto García, Alejandro: "La idea del ius puniendi único del Estado, que en el capítulo anterior se ha examinado críticamente, tiene su origen y alcanza su última justificación en una maniobra teórica que en Derecho se utiliza con cierta frecuencia: cuando la Doctrina o la Jurisprudencia quieren asimilar dos figuras aparentemente distintas, forman con ellas un concepto superior y único, un supraconcepto, en el que ambas están integradas, garantizándose con la pretendida 


\section{Andrés Varela}

144). No obstante, reconocemos como lo hace Nieto García respecto al Derecho Administrativo Sancionatorio, que en el Derecho Aduanero Sancionatorio se debe avanzar a una dogmática sancionatoria propia (Nieto 2012, 153-156).

Así, pese a sus particularidades específicas, que merecen su tratamiento dogmático propio, coincidimos con García Vizcaino en cuanto a la naturaleza penal de las disposiciones que regulan las infracciones y los delitos aduaneros (García 2010, 404) (Camauër 2007, 295). Asimismo, debemos remarcar la ausencia de diferencias ontológicas entre delitos e infracciones aduaneras, y sí, solamente, la existencia de diferencias cuantitativas, que se manifiestan a través de las penas que se imponen en uno u otro caso (García 2010, 407) ${ }^{(7)}$.

En lo que aquí interesa, referiremos exclusivamente al campo infraccional (o también denominado en algunos países como contravencional), puesto que es en éste en el que se presenta la pugna sobre la subsistencia o pervivencia del régimen de responsabilidad objetiva.

Así, partiendo del estudio de la finalidad de las infracciones y sanciones, y de los regímenes de imputación de su responsabilidad, relevaremos las razones que se han esgrimido para el establecimiento del régimen de responsabilidad objetiva y su actual pervivencia, y las críticas que merecen tales fundamentos.

No obstante, no nos quedaremos en dicho punto sino que evaluaremos la alternativa jurídica que a nuestro juicio permite la sustitución definitiva del régimen de responsabilidad objetiva por un régimen de responsabilidad subjetiva, esto es, mediante el aditamento de presunciones legales relativas, que posibilitan, sin vulneren los derechos de los administrados al juzgar las infracciones aduaneras, presumir exclusivamente la intención (dolo), cuando ella sea de difícil comprobación para el Fisco.

\section{Infracciones y sanciones aduaneras: su fínalidad y la imputación de su responsabilidad}

No todo incumplimiento de un precepto normativo tiene como resultado la imposición de una sanción. Así, sin perjuicio de que una determinada norma ordene realizar o abstenerse de realizar una conducta determinada, su incumplimiento (por acción u omisión) no tiene como consecuencia per se la aplicación de una sanción.

Para que el incumplimiento de un determinado precepto tenga como consecuencia la aplicación de una sanción, se requiere, en primer término, que esa conducta (activa u omisiva) haya sido previamente seleccionada por una norma de rango legal (en aplicación del principio de legalidad) como de entidad suficiente para que quien la realice sea pasible de una determinada sanción; y, en segundo término, que mediante un procedimiento administrativo o un proceso judicial se

identidad ontológica la unidad del régimen. Esto es lo que se ha hecho con la potestad sancionadora del Estado, en la que se engloban sus dos manifestaciones represoras: la judicial penal y la administrativa sancionadora. Una técnica que se reproduce simétricamente con el supraconcepto de ilícito común, en el que se engloban las variedades de los ilícito penal y administrativo, y que se corona, en fin, con la creación de un Derecho punitivo único, desdoblado, en el Derecho Penal y en el Derecho Administrativo Sancionador.

Potestades, ilícitos, Ordenamientos y Derecho se integran así en un edificio único de sorprendente armonía, en el que todos sus elementos parecen encajar con suavidad, se evitan contradicciones y tensiones tradicionales y hasta se crean sinergias dogmáticas, puesto que los avances técnicos que se consiguen en un campo, se traspasan inmediatamente al cuerpo común. En nuestro caso concreto, gracias a los supraconceptos se ha podido crear un sistema de estructura piramidal coronado por el ius puniendi del Estado: cúspide en donde convergen las líneas de todas las potestades represivas". Nieto García, Alejandro, Derecho Administrativo Sancionador, $5^{a}$ ed. (Madrid: Editorial Tecnos, 2012), 124.

(7) En igual sentido se expresa Pablo Labandera, "Estudios sobre el Código Aduanero de la RoU," en Código Aduanero de la República Oriental del Uruguay. $2^{\text {a }}$ ed. (Montevideo: La Ley, 2016), 432. 


\section{Una necesidad imprescindible: Desterrar definitivamente el régimen de responsabilidad objetiva del infraccional aduanero An essential need: Banishing permanently strict liability from the customs infringement procedures}

constaten una serie de elementos, requeridos a dicho actuar, para que le sea atribuido al sujeto que haya sido autor de tal acción u omisión las consecuencias jurídicas previstas en aquella norma, salvo que dicha norma (u otra norma legal) le atribuya a otro sujeto las consecuencias jurídicas del actuar del primero (junto a aquel o en lugar de aquel)(8)(9).

Ahora bien, no debe olvidarse que la imputación ${ }^{(10)}$ de cualquier hecho supuestamente infraccional (al igual que en todo el ámbito del Derecho Sancionatorio), debe estar acompañada de la prueba acerca de algún tipo de participación de los supuestos responsables o, en su caso, del nexo jurídico existente entre el sujeto a quien se le pretende imputar la consecuencia de la infracción y quien actuó la conducta descripta en aquella norma, nexo jurídico que, claro está, debe determinarse en una norma de rango legal.

Respecto a este último punto conviene evocar la posición de Nieto García, al recordar la distinción entre autoría y responsabilidad, puesto que, aun cuando normalmente el autor es el responsable, en determinadas ocasiones la propia Ley determina su disociación, y así, si bien en el primer caso se exige culpabilidad del actor, en el segundo caso la imputación de responsabilidad es realizada ex lege, y por tanto no precisa de la culpabilidad, siendo un supuesto excepcional al principio de personalidad de la pena ${ }^{(11)}$. Así, cabe recordar también que, por tratarse esa norma de una norma especial, siendo que el principio general es el de personalidad de la pena (esto es, que quien es sancionado sea quien produjo el hecho), requiere una norma de imputación especial, y ella, dado su carácter excepcional, debe ser de interpretación restrictiva.

El principio de personalidad de la pena implica que sólo será punible quien sea culpable, es decir a quien la acción punible pueda ser atribuida tanto objetiva como subjetivamente (Navarrini y Asorey 2000, 109). Las infracciones aduaneras son, en esencia, descripciones de conductas antijurídicas, cuyo cumplimiento por un sujeto, que actúa la conducta descripta, haciendo u omitiendo hacer la misma, tiene como resultado la imposición de una sanción.

Siguiendo a Cotter, son infracciones aduaneras los hechos, actos u omisiones que se reprimen por trasgredir las disposiciones de la legislación aduanera respectiva (Cotter 2014, 1147). En tal sentido, compartimos con la Profesora uruguaya de Derecho Financiero Addy Mazz, que el concepto de infracciones aduaneras es muy amplio, en el sentido de

(8) Como es el caso de los Despachantes de Aduana en el régimen aduanero uruguayo, dado el numeral 3 del artículo 218 del Código Aduanero de la República Oriental del Uruguay (aprobado por Ley No. 19.276, de 19 de Septiembre de 2014) que dispone:

"3. El despachante de aduana, independientemente de su eventual responsabilidad por la infracción aduanera, será responsable por el pago de la sanción pecuniaria solidariamente con el remitente, consignatario, importador, transitador, exportador o persona que tenga la disponibilidad jurídica de la mercadería".

(9) En igual sentido, el artículo 219 del Código Aduanero de la República Oriental del Uruguay establece:

"Artículo 219. Otros responsables.-

1. Las personas físicas o jurídicas son solidariamente responsables con sus apoderados o dependientes por las infracciones aduaneras cometidas por estos en el ejercicio de sus funciones.

2. Los directores, administradores y representantes legales y voluntarios de las personas jurídicas, que no procedan con la debida diligencia en sus funciones, responderán solidariamente por el pago de los tributos y las multas impuestas por infracciones aduaneras a las mismas. Esta responsabilidad se limita al valor de los bienes que administren o dispongan, salvo que hubieren actuado con dolo.

3. Si no hubiere despachante de aduana o solicitante de la operación, responderán solidariamente por las infracciones aduaneras el que conduzca las mercaderías y el que tenga la disponibilidad jurídica de las mismas."

(10) Conforme García Vizcaino, imputar es atribuir un hecho a un sujeto. García Vizcaino, Catalina, "Infracciones aduaneras", voz contenida en Enciclopedia Jurídica Omeba, Apéndice, t. V, Buenos Aires, 1986.

(11) Cónfer Alejandro Nieto García, Derecho Administrativo Sancionador (Madrid: Editorial Tecnos, 2012 ), 414 - 27. 


\section{Andrés Varela}

las conductas que atrapa y sanciona. Puesto que no solo se relaciona con la infracción a las normas tributarias aduaneras, sino con la violación de cualquier norma de Derecho Aduanero, tanto aquellas que configuran obligaciones tributarias aduaneras, como las que regulan los procedimientos, el control, y extendemos nosotros, las que regulan los regímenes de prohibiciones (Mazz 2001, 261) $)^{(12)}$.

Ahora bien, según la corriente penal, mediante la imposición de las sanciones a las infracciones aduaneras, que pueden ser multa o comisos, se pretende disuadir o intimidar, y llegado el caso castigar a quien fue autor de la acción disvaliosa; en cambio, para la corriente administrativista, se busca compensar el daño causado por la acción disvaliosa (Cotter 2011)(13).

Nos inclinamos absolutamente por el carácter penal de las infracciones aduaneras, en tanto que las sanciones se presentan como disuasivos al incumplimiento de la conducta requerida por el ordenamiento, y tiene como segundo efecto, saltada la valla del primero, el de imponer un castigo a quien la realice, con marcado efecto ejemplificaste. En tal sentido, en tanto que la finalidad se dirige a evitar las conductas que quebranten el ordenamiento normativo aduanero, es necesario requerir el análisis de la conducta del autor del resultado contrario a la norma, y ello, a efectos de sancionar al autor de la misma.

Así, en términos generales, puede afirmarse que para la Doctrina Penal ${ }^{(14)}$, cuyos conceptos resultan extensibles a todo el Derecho Sancionatorio como lo es el Derecho Aduanero Sancionatorio, y en particular el Infraccional Aduanero, una acción típica y antijurídica, sólo es culpable si le puede ser reprochado al sujeto, en la situación concreta en que se hallaba, que hubiera obrado en contra de las exigencias del Ordenamiento Jurídico.

El principio de culpabilidad que informa a todo el Derecho Sancionatorio, requiere del análisis de la conducta asumida por el autor de la misma. Se habla así, de culpabilidad en sentido estricto(15), o imputación de la conducta al autor, que se configura como un elemento esencial de la infracción, en el que se examina si al sujeto se le puede reprochar la infracción de la norma de determinación; esto es, la realización de la acción u omisión típica y antijurídica.

Y ello sólo es posible si esa persona, en la situación concreta en que se hallaba, podía obrar de otro modo, de acuerdo con la información con que contaba y/o con las exigencias del Ordenamiento Jurídico correspondiente (De Palma 1996, 60-61). Así, estos requerimientos, que se formalizan en principios (Quintero 1991, 253-293), no son más que una exigencia de rango constitucional, ya que la regulación del aparato sancionador del Estado está sometida a los postulados del Estado de Derecho.

Entre dichos principios se halla el de culpabilidad, así como todas sus manifestaciones o exigencias. La dignidad de la persona, que configura el concepto de persona y que subyace al principio de Estado de Derecho, impone al Legislador, primero; y al intérprete y aplicador de la ley, después, la obligación de respetar las exigencias de dichos principios, y en su mérito, resulta esencial la necesidad de imputar la responsabilidad, únicamente a un sujeto que efectivamente haya participado en la comisión de una infracción, como consecuencia, además, de manera complementaria, del principio de personalidad de las sanciones; que la conducta típica, antijurídica y culpable pueda ser además reprochable a su autor

(12) En igual sentido García Vizcaino, Catalina, Infracciones aduaneras, 407.

(13) Ampliamente se pude ver las distintas corrientes en torno al tema en García Vizcaino, Catalina, Infracciones aduaneras, $394-409$.

(14) Véase por todos: Cerezo Mir, José. Curso de Derecho Penal Español. Parte General, Volumen III (Madrid: Editorial Tecnos, 2001), 15 y siguientes, 135-136, y 522 y siguientes; y Roxin, Claus. Derecho Penal. Parte General, Tomo I. Fundamentos. La Estructura de la Teoría del Delito. (Madrid: Editorial Civitas, 1997), 791 y siguientes.

(15) Ídem. 


\section{Una necesidad imprescindible: Desterrar definitivamente el régimen de responsabilidad objetiva del infraccional aduanero An essential need: Banishing permanently strict liability from the customs infringement procedures}

o culpabilidad estricto sensu; y por último, la exigencia de responsabilidad por la acción, que enlaza con el principio de legalidad y su exigencia de tipicidad(16).

En tal sentido se ha dicho que "culpabilidad es reprochabilidad. Con el juicio desvalorativo de culpabilidad se reprocha al autor que no ha actuado conforme a derecho, que se ha decidido a favor del ilícito, aun cuando podía comportarse conforme a derecho" (Palabras del Tribunal Alemán citado por García Vizcaino 2010, 420).

Ha expresado Soler, con absoluta claridad, que la reprochabilidad del derecho con relación a una acción delictuosa, y extendemos a todas las ilícitas, como las infraccionales, se basa en el juicio de valor acerca de lo que el sujeto ha querido hacer, para lo cual corresponde determinar si su voluntad, libremente ejercida, estuvo dirigida al propósito de delinquir o si, al menos, aun cuando no haya querido oponerse al precepto normativo, lo contradijo por no haber puesto en la acción el deber de cuidado requerido. En tales casos, concluye Soler, habiéndose verificado los presupuestos subjetivos, existe culpabilidad, y ésta, unida a la acción típica antijurídica configura el delito, o la infracción (Solar 2001, 74).

De tal forma, en la responsabilidad subjetiva, el factor de atribución del hecho ilícito y dañoso al sujeto (el infractor, en el caso) al que se pretende responsabilizar lo constituye la propia conducta desarrollada por ese individuo, cuya actuación personal genera la responsabilidad que se le imputa. Los factores de atribución subjetivos son la culpa y el dolo.

Así, la culpabilidad puede ser a título de dolo (voluntad deliberada dirigida hacia la transgresión) o por culpa (voluntad que por falta de precaución no actúa como la ley exige; puede ser por imprudencia, negligencia, impericia en el arte o profesión, inobservancia de reglamentos o deberes del cargo) (García Vizcaino 2010, 420).

En tal sentido, ha expresado Soler que, así como en el dolo su individualización se hace en base a su finalidad, en la culpa en cambio, la conducta se evalúa en razón de los medios con los cuales el fin se ha obtenido. Así, dice Soler, se hace necesario determinar si la conducta del sujeto ha sido la adecuada en el caso concreto, es decir, si su accionar ha sido diligente teniendo en cuenta los cánones culturales usuales que rigen la acción que se le imputa, o si, por el contrario, ha actuado con negligencia o imprudencia ocasionando un daño que podría haber evitado si su gestión se hubiera ajustado a las pautas sociales de cuidado, las que, a su vez, deben evaluarse teniendo en cuenta las condiciones particulares del sujeto (Solar 2001, 76).

Concluyendo por ello Soler, que las condiciones particulares del sujeto y su relación con las pautas sociales o normativas es lo que permite individualizar la conducta culposa, pero además, que tal individualización no solo debe realizarse a la descripción del tipo en abstracto, sino que es necesario completar el tipo acudiendo a datos extrapenales, esto es, recurriendo a la consideración del poder concreto de evitar el menosprecio que el sujeto tenía y del cual podía hacer uso, poder que se relaciona a la condición personal del sujeto, ya que es mayor la exigencia requerida a un especialista que a un profano en una actividad determinada (verbi gratia Despachante de Aduana) (Solar 2001, 76).

Finalmente, el grado de subjetividad requerida por el ordenamiento legal para la configuración de la infracción va a surgir de la ley en la descripción del tipo infraccional, básicamente de su verbo nuclear, esto es si el mismo requiere dolo solamente, o si se admite culpa.

\section{El régimen de responsabilidad objetiva}

En la responsabilidad objetiva, en cambio, se prescinde del elemento culpabilidad (elemento subjetivo) a efectos de responsabilizar a un sujeto por ocasionar un resultado contrario a la norma. La infracción se configura con la simple inobservancia del precepto (elemento objetivo),

(16) Un tratamiento amplio al respecto puede verse en Pablo Labandera, "Estudios sobre el Código Aduanero de la ROU," en Código Aduanero de la República Oriental del Uruguay. $2^{\mathrm{a}}$ ed. (Montevideo: La Ley, 2016), 497-514. 
Andrés Varela

independientemente de la voluntad del sujeto (elemento subjetivo) (Altamirano 2012, 684).

Así, en aquellos supuestos en los que se consagra este tipo de responsabilidad no es posible exonerarse de la misma en consideración del elemento culpabilidad. En estos, por expresa previsión legal, es indiferente la verificación del elemento subjetivo, esto es, la conducta del sujeto, solo siendo verificable el nexo entre la acción de la conducta y el sujeto.

Por ello, la expresión responsabilidad objetiva significa responder el autor por el resultado (tanto en delitos o infracciones dolosos como culposos), siempre que esté presente una relación de causalidad con la conducta, aun en aquellos casos en que (subjetivamente) no haya actuado con dolo o culpa (De Jesús 2006, 42).

Debe tenerse presente que las infracciones se producen mediante una acción o hecho humano voluntario, por tanto, normalmente, incluyen o entrañan una intención dolosa o un obrar culposo.

Por ello, debe entenderse que el elemento subjetivo está siempre en el actuar de la conducta del sujeto que comete la infracción, no obstante, y como con enjundiosa precisión lo establece Camauër, la cuestión central se encuentra en saber si la Ley lo ha tomado en cuenta o no y, asimismo, en qué medida lo hace, para atribuirle a su autor el resultado disvalioso previsto en la norma, esto es, la imposición de la sanción (Camauër 2007, 303).

Así, Camauër refiere a la forma de imputación bajo un régimen de responsabilidad objetiva, como impuesta por una ley a priori, como una responsabilidad de tipo mecanicista, que prescinde de toda subjetividad en la consideración de la conducta sancionable (Camauër 2007, 303).

\section{4. ¿Que protege el régimen de responsabilidad objetiva en las infracciones aduaneras? Las posibles causas alegadas para pretender la supervivencia del régimen}

Ahora bien, como hemos referido al inicio, y que resulta de amplio conocimiento, en Latinoamérica aún subsiste la imputación de responsabilidad en materia de infracciones (o contravenciones) aduaneras, bajo un régimen de responsabilidad objetiva.

Por tanto, veamos algunos de los argumentos sostenidos para excluir de las infracciones aduaneras toda consideración del elemento subjetivo (culpabilidad) e imputar al autor de la conducta su responsabilidad por el resultado exteriorizado de su conducta, esto es, objetivando la responsabilidad.

Así, puede referirse sucintamente a dos de los argumentos justificantes centrales que han sido alegados y referidos para sostener la conveniencia y/o pervivencia del régimen de responsabilidad objetiva. A saber: a) las dificultades para determinar y probar la conducta dolosa o culposa por parte del Fisco; y b) la trascendencia de la defensa de la renta aduanera eludida.

\subsection{Dificultades para determinar y probar la conducta dolosa o culposa por parte del Fisco}

Uno de los argumentos sostenidos ha sido, y es, el de la dificultad de probar la conducta dolosa o culposa para el Fisco. No obstante, si bien ello puede ser considerado en relación al dolo, dadas las particularidades que presentan las conductas dolosas en materia de infracciones aduaneras (al igual que las fiscales), principalmente relacionadas a las conductas en fraude a las normas aduaneras (defraudación en general, y algunas de las modalidades de contrabando), ello no justifica en nada trasgredir el principio de culpabilidad prenombrado, en aras de corregir esa dificultad probatoria, cercenando de tal modo toda defensa del eventual imputado, como tampoco, extender dichas consecuencias a las conductas culposas.

Entendemos que existen otros remedios para dichas falencias probatorias que, bien utilizados por el Legislador, pueden tender 


\section{Una necesidad imprescindible: Desterrar definitivamente el régimen de responsabilidad objetiva del infraccional aduanero An essential need: Banishing permanently strict liability from the customs infringement procedures}

al ponderado equilibrio de éstas, y el respeto de los sujetos potencialmente encausados.

En tal sentido, como claramente advierten Navarrini y Asorey, al analizar las presunciones en materia tributaria, y pretendiendo determinar el fenómeno que las produce, existen enormes dificultades al pretender captar la identificación de la realidad, esto es, el comportamiento en fraude a la ley fiscal, así como la voluntad o intención del sujeto en actuar dicha conducta, como también los problemas que plantea la prueba de la existencia del comportamiento fraudulento (Navarrini y Asorey 2000,106 ). Dicen los autores que, dada la estructura de la norma fiscal, donde se detecta un supuesto de hecho que es configurador del nacimiento de una conducta a seguir, el fraude a la ley fiscal consiste en ocultar la realización efectiva de ese hecho configurador de la conducta o mandato, simulando jurídicamente un hecho distinto $u$ ocultando el verdadero hecho ocurrido (Navarrini y Asorey 2000, 106).

Ahora bien, basado en dicha circunstancia Giuliani Fonrouge ha expresado, en relación al Derecho Tributario, que la dificultad para determinar el elemento subjetivo en el acto delictivo financiero haría ilusoria muchas normas represivas, de modo que es preciso sancionar, como principio general, que basta la objetividad de la transgresión para que exista infracción punible sin excluir la necesidad de apreciar la conducta del sujeto en ciertos casos especiales (Giuliani 1962, 648).

Obsérvese que, dadas las dificultades aludidas, y en procura de facilitar el atrapar las conductas que son de difícil determinación, imputando la responsabilidad bajo un régimen de responsabilidad objetiva se desconoce frontalmente la finalidad última de la sanción en las infracciones, que es evitar o corregir las conductas en contra el ordenamiento.

Así, bajo un régimen de responsabilidad objetiva, aun cuando el actor de la conducta tuviera causas que justificaran el comportamiento realizado, esto es, el que tuvo como resultado la trasgresión de la norma, le es vedada la justificación, produciéndose la consecuencia prevista en la infracción, esto es, la sanción. Por tanto, puede ser que el actor de la conducta no pudiera haber actuado de modo distinto, y aun ello, se le impute la infracción y se le imponga una sanción.

Así, si entendemos que la sanción tiene como finalidad, una vez producida la acción, castigar a quien actúa contrariando la norma, bajo el régimen de responsabilidad objetiva será indiferente si lo hace con intención, con negligencia, con error, o si tendría causas de justificación de aquella.

El efecto que produce el régimen de responsabilidad objetiva es el de atrapar el resultado de la conducta, y no a la conducta misma $y$, por tanto, es ineficiente para dirigirse a corregirla, puesto que castiga a todas por igual. Todo lo cual se aleja definitivamente de la función de la sanción, que es castigar al autor de la conducta, con la finalidad de reprimir las conductas contrarias al ordenamiento, cuando la misma se dirijan al quebrantamiento de sus normas, fuera porque el sujeto actuó con intención de dicho resultado disvalioso, o fuera que actuó de forma negligente o imprudente, y todos ello, con un claro efecto ejemplificante. Por tanto, será indiferente la conducta que realice el sujeto y sí, solamente, su resultado.

No puede justificarse en base a las dificultades de comprobación de la conducta dolosa, ya que en el campo de la conducta culposa entendemos que estrictamente dichas dificultades no se presentan, que se desconozca al sujeto la posibilidad de toda defensa en relación a la conducta asumida $y$, asimismo, se vaya en contra de la propia finalidad de la sanción.

En definitiva, la alegada justificación en torno a la dificultad probatoria de la conducta del actor constituye una prerrogativa instrumental que desconoce el principio de responsabilidad subjetiva, cuyo fundamento de punición se halla en la conducta del actor.

\subsection{La trascendencia o defensa de la renta} aduanera eludida

Finalmente, otro de los argumentos sostenidos, a impulso de la tesis administrativista, ha sido el del perjuicio económico para la Hacienda Pública, o en el resultado que dicha 
Andrés Varela

trasgresión produce, en particular, en la percepción de los tributos aduaneros ${ }^{(17)}$.

No obstante, como bien recuerda Mazz, la trascendencia de los tributos aduaneros, o de la renta aduanera para la economía del país como argumento para el mantenimiento del régimen de responsabilidad objetiva resulta inoperante, máxime teniendo en consideración que los impuestos internos, y entre ellos los indirectos, son los que aportan mayor parte de los ingresos en el país, y si en las infracciones a éstos se rige el régimen de responsabilidad subjetivo, esto es por la culpabilidad, no se justifica la inaplicación de dichas normas generales a los impuestos aduaneros (Mazz2001, 273).

Con lo visto podemos concluir (como lo anunciáramos al comienzo) que no existe una justificación jurídica para el mantenimiento del régimen de responsabilidad objetiva en materia de infracciones aduaneras. Asimismo, con la Doctrina Tributarista más destacada podemos concluir, que el régimen de responsabilidad objetiva, como excepción a la aplicación del principio general de responsabilidad subjetiva en materia infraccional, es una manifestación de primitivismo jurídico(18).

\section{El caso de Uruguay: Grandes avances del CAROU, dificultades actuales, y otras batallas dogmáticas para dar y vencer}

En el caso de la legislación aduanera de la República Oriental del Uruguay, con la aprobación del Código Aduanero de la República Oriental del Uruguay (En adelante, "CAROU") (aprobado por Ley No. 19.276, de 19 de Septiembre de $\left.2014^{(19)}\right)$, el régimen de responsabilidad en las infracciones aduaneras ha pasado de ser imputado en un régimen de responsabilidad objetiva, en la mayoría de las infracciones ${ }^{(20)}$ (a excepción de la defraudación de valor $\left.{ }^{(21)}\right)$, a serlo bajo un régimen de responsabilidad subjetiva (a excepción de las infracciones de Contravención y de Diferencia).

Es conveniente aclarar, previo a seguir avanzando en lo que refiere al contenido del

(17) Cónfer Del Cueto, José. El contencioso Aduanero. Ubicación e Interpretación (Montevideo: Editorial Amalio M. Fernández, 1970), 57. González, Ariosto D., Derecho Aduanero Uruguayo. Comentarios de la Legislación Represiva (Montevideo: Editorial Claudio García y Cia, 1946), 25 - 45.

(18) Véase Ramón Valdés Costa, Nelly Valdes de Blengio y Enrique Sayagues Areco, Código Tributario concordado y anotado (Montevideo: Editorial FCU, 2002), 532 citan a Valdés Costa, Ramón; Modelo de Código Tributario del Centro Latinoamericano de Administradores Tributarios (CIAT), (Secretaria del CIAT, 1997) citados por Labandera, Pablo, "EI Derecho Aduanero en Uruguay”, en Cotter, Juan P., Derecho Aduanero, 1ª ed., Tomo III (Buenos Aires: Abeledo-Perrot, 2014), 2050.

(19) Accesible en: Centro de Información Oficial, Normativa y Avisos Legales del Uruguay, Código Aduanero No. 19276, http:// www.impo.com.uy/bases/codigo-aduanero/19276-2014

(20) El artículo 287 de la Ley 13.318, de 28 de diciembre de 1964, disponía:

"En los casos de infracción aduanera no será admisible ninguna excusa fundada en la buena fe, en el error propio o ajeno o en la falta de intención de perjudicar o defraudar al Fisco, sin perjuicio de lo que dispongan leyes especiales".

(21) La infracción de defraudación de valor estaba originalmente prevista en el artículo 13 de la Ley 14629, de 5 de Enero de 1977, en que se disponía:

"Artículo 13.

Las modificaciones de valor en las importaciones o despachos constituirán la infracción aduanera de defraudación siempre que se compruebe el dolo del importador, no siendo aplicable en ese caso lo dispuesto en el artículo $287^{\circ}$ de la ley 13.318 , de 28 de diciembre de 1964.

Se presumirá la defraudación, sin perjuicio de la prueba en contrario, en los siguientes casos:

A) Cuando el precio normal fijado de acuerdo a las normas de valoración de Bruselas por la Dirección Nacional de Aduanas, supere como mínimo en un $100 \%$ (cien por ciento) el valor declarado por el importador; o

B) Cuando se omitan o se establezcan incorrectamente, los datos en los respectivos formularios, que para control de la valoración, impongan la Dirección Nacional de Aduanas.

Si los hechos dieren lugar simultáneamente a más de una infracción aduanera sólo se aplicará la sanción mayor. 


\section{Una necesidad imprescindible: Desterrar definitivamente el régimen de responsabilidad objetiva del infraccional aduanero An essential need: Banishing permanently strict liability from the customs infringement procedures}

presente, que las infracciones aduanero, desde la entrada en vigencia del CAROU, son juzgadas exclusivamente por el Poder Judicial (salvo el caso de las Contravenciones, en las cuales son procesables en vía administrativa frente a la Dirección Nacional de Aduanas, y son pasibles de recursos, Recursos de Revocación y Jerárquico, y eventualmente son anulables las resoluciones administrativas que dicte aquella Dirección ante el Tribunal de lo Contencioso Administrativo)(22).

Ahora bien, el régimen de responsabilidad objetiva, que previo a la entrada en vigencia del CAROU, pesaba sobre el presunto infractor en las referidas infracciones, hacía que la desidia probatoria fuera bastante extendido en la práctica por parte de quienes eran titulares de la acción fiscal (Representante Fiscal)(23), dado que éstos últimos gozaban del beneficio legal de tener que probar exclusivamente el acaecimiento de los hechos previstos en el supuesto de hecho normativo de cada infracción y su vinculación con el sujeto imputado (como autor o responsable del mismo), para con ello pretender la

Lo dispuesto en este artículo, referido a responsabilidad, rige exclusivamente para diferencias de valor, no derogando el artículo $284^{\circ}$ de la ley 13.318 , de 28 de diciembre de $1964^{\prime \prime}$.

mmPosteriormente, dicho artículo fue modificado por la redacción dada por el artículo 150 de la Ley $N^{\circ} 16.320$, de $1^{\circ}$ de Noviembre de 1992, no obstante, tanto la Jurisprudencia como la Doctrina Nacional entendían que le era aplicable el régimen de responsabilidad subjetiva, y que requería de dolo.

Así, dicho artículo disponía:

"Artículo 13. Las acciones u omisiones que tiendan a distorsionar u ocultar el precio normal de las mercaderías a importar, definido como tal por la presente ley, constituirán la infracción aduanera de defraudación.

Se presumirá la defraudación cuando:

A) Se compruebe la presentación de declaraciones inexactas o incompletas que pretendan desvirtuar el valor imponible de los tributos;

B) Se compruebe la adulteración de documentos o registros contables de los importadores, relacionados con la operación aduanera de importación que corresponda;

C) El precio normal determinado por la Dirección Nacional de Aduanas supere como mínimo en un 100\% (cien por ciento), el valor declarado por el importador.

En los casos de defraudación se impondrá una multa igual al doble del importe de los gravámenes adeudados, siendo ésta también de cargo del importador.

Si los hechos dieran lugar simultáneamente a más de una infracción aduanera, se aplicará la sanción mayor.

La responsabilidad de estas infracciones será siempre del importador de la mercadería o de su mandante si actuara por poder. Esta responsabilidad será sin perjuicio de la subsidiaria que se pueda hacer efectiva contra el despachante o solicitante de la operación.

Lo dispuesto en este artículo referido a la responsabilidad rige, exclusivamente para diferencias de valor, no excluyendo lo dispuesto por el artículo 284 de la Ley No 13.318, de 28 de diciembre de 1964".

(22) El artículo 227 del CAROU dispone:

"Artículo 227. Competencia según materia.-

1. El conocimiento de los asuntos relativos a infracciones aduaneras, excepto la infracción de contravención y lo dispuesto en el artículo 232 de este Código, corresponderá a los Juzgados Letrados de Primera Instancia del interior con competencia en materia aduanera y a los Juzgados Letrados de Aduana en los departamentos de Canelones y de Montevideo.

2. Conocerán los Tribunales de Apelaciones en lo Civil en segunda instancia y la Suprema Corte de Justicia en el recurso de casación, en caso de corresponder".

(23) Previo a la entrada del CAROU, el artículo 258 de la Ley No. 13.318, de en la redacción dada por el artículo 6 del Decreto Ley No. 15.648, de 22 Octubre de 1984, disponía que:

"Artículo 258. El ejercicio del Ministerio Fiscal o la representación del Fisco ante la Secretaría de lo Contencioso Aduanero, los Juzgados Letrados de Aduana, los Tribunales de Apelaciones en lo Civil y ante la Suprema Corte de Justicia únicamente en los casos de inconstitucionalidad y de casación, incumbirá a los Fiscales Letrados Nacionales de Aduana. Ante las Receptorías de Aduana y los Juzgados Letrados de Primera Instancia del Interior, dicha representación estará a cargo de los Fiscales Letrados Departamentales de la respectiva jurisdicción". 


\section{Andrés Varela}

imputación y posterior condena del imputado, cuando en no menos veces, se veían favorecidos incluso de determinadas presunciones respecto a este elemento objetivo (verbi gratia contrabando). Por su parte, el denunciado (eventual imputado) no podía aducir elemento subjetivo alguno que enervaran su culpabilidad.

La aplicación mecanicista que pretendía consolidar la referida legislación fue matizada por construcciones pretorianas de la Jurisprudencia, que comenzó a introducir, y luego definitivamente consolidó, el criterio de benignidad o criterio de flexibilidad ${ }^{(24)}$, atenuando así el principio de responsabilidad objetiva previsto a texto expreso en el artículo 287 de la Ley 13.318, de 28 de Diciembre de $1964^{(25)}$, hoy derogado, pero simultáneamente incorporado al numeral 3 del artículo 213 CAROU para las Infracciones de Diferencia y Contravención.

Así, el tratamiento diferenciado según el tipo infraccional se encuentra actualmente consagrado en el artículo 213 del CAROU, que dispone:

"Artículo 213) (Responsabilidad).-

1. Las infracciones aduaneras de defraudación, defraudación de valor, desvío de exoneraciones y contrabando se imputarán a título de culpa o dolo.

2. La multa por las infracciones referidas en el numeral anterior podrá reducirse hasta en un 50\% (cincuenta por ciento) en caso que se pruebe haber actuado con culpa.

3. En las infracciones aduaneras de contravención y de diferencia no será admisible ninguna excusa fundada en la buena fe, en el error propio o ajeno o en la falta de intención de perjudicar o defraudar al Fisco."

Según puede observarse, el artículo transcripto no ha recogido de manera expresa la designación del régimen aplicable a las infracciones, esto es, no ha dicho responsabilidad subjetiva, en el primer caso, aplicable al elenco de las todas las infracciones aduaneras previstas, con excepción de la Contravención y la de Diferencia, y respecto a éstas, que se imputan bajo un régimen de responsabilidad objetiva. Por el contrario, ha designado en un caso, el del numeral 1 , que incluye a las infracciones aduaneras de Defraudación, Defraudación de valor, Desvío de exoneraciones y Contrabando, que éstas se imputarán a título de culpa o dolo. Por su parte, en el numeral 3 , y en relación a las infracciones de Contravención y de Diferencia, ha expresado que respecto a éstas no será admisible ninguna excusa fundada en la buena fe, en el error propio o ajeno o en la falta de intención de perjudicar o defraudar al Fisco.

(24) Como simple muestra de ello se puede observar la invocación de tales "criterios" en la Sentencia No. 267/2011, de 14 de Octubre de 2011: "En tal marco, si bien no escapa al criterio de la Sala que el art. 287 de la ley 13.318 consagra el principio de la responsabilidad objetiva en esta materia, tampoco la pertinencia de la aplicación subsidiaria de las normas de procesales de derecho común" (artículo. 279 de la misma ley; 4 del Código General del Proceso).

En tal sentido ha previamente adherido a la jurisprudencia que adopta un criterio de benignidad o flexibilidad para rechazar excesos en una concepción rígida del represivo aduanero, evitando excesos en la interpretación mecánica y objetiva de las normas que tipifican hechos infraccionales aduaneros (TAC 6 turno, sent. de 10/9/93 en L.J.U. No. 12.731), admitiendo incluso que la duda favorece al acusado y la invocación de causas de justificación (TAC 1 L.J.U. No. 11.510). Y aún la buena fe, en el entendido de que se está actuando conforme a derecho (TAC 4 L.J.U No. 10.350), considerándola como una pauta valorativa universal de la conducta humana que alcanzaría también al proceso aduanero (todas citas del TAC 6 mencionado; de la Sede sentencia No. 118/00, 173/10; en igual sentido, TAC 5 No. 185 de 12/9/01)". Accesible en www. bjn.poderjudicial.gub.uy

(25) En relación con la postura de la Doctrina y Jurisprudencia Uruguaya respecto al régimen de responsabilidad objetiva, véase ampliamente: Pablo Labandera, "Estudios sobre el Código Aduanero de la ROU”, en Código Aduanero de la República Oriental del Uruguay. $2^{a}$ ed. (Montevideo: La Ley, 2016), 504-14; y Mazz, Addy, La integración económica y la tributación (Montevideo: Fundación de Cultura Universitaria, 2001), 270-74. 


\section{Una necesidad imprescindible: Desterrar definitivamente el régimen de responsabilidad objetiva del infraccional aduanero An essential need: Banishing permanently strict liability from the customs infringement procedures}

Así, tal forma de referir el Legislador al régimen de responsabilidad en la imputación de las consecuencias de la conducta infraccionales, y de la consideración o no del elemento subjetivo (culpabilidad), ha derivado en algunas divergencias de la Doctrina aduanera nacional al poder encontrar sustento normativo al analizar los tipos infraccionales de las infracciones de Defraudación, Defraudación de Valor y Contrabando, dado que, de una lectura de sus tipos infraccionales, se deriva una descripción que permitiría imputar conductas exclusivamente a título de dolo, en tanto que el artículo 213 CAROU refiere a que la imputación de tales infracciones se realiza a título de dolo o culpa, reiteramos, dice se imputarán a título de culpa o dolo. Entendiéndose por la más destacada Doctrina nacional que en tal sentido debería primar este último artículo (Labandera 2016, 449).

No obstante, hemos entendido ${ }^{(26)}$ que lo que ha existido es un error del Poder Ejecutivo, no corregido por el Legislador ${ }^{(27)}$, y ello, en dos sentidos: en primer término, al referirse al régimen de responsabilidad (subjetiva u objetiva) según la forma de imputar ("se imputarán"), o de no admitir excusas (no será admisible ninguna excusa); $y$, en segundo término, al establecer un régimen general que no encuentra adecuación en la lectura de cada uno de los tipos infraccionales previstos.

Así, puede comprobarse que, al aludir al régimen de imputación de la responsabilidad por infracciones aduaneras en la Exposición de Motivos del Poder Ejecutivo que acompañó el Proyecto de Código Aduanero de la República Oriental del Uruguay, se dispuso al respecto que:

"EI CAROU, a efectos de atenuar la rigurosidad del sistema vigente, consagra la responsabilidad subjetiva para las infracciones de defraudación, defraudación de valor, desvío de exoneración y contrabando, las que pasan a imputar sólo a título de culpa o dolo. Asimismo, para el caso de culpa, las sanciones pueden reducirse hasta un $50 \%$. Por su parte, para las infracciones de contravención y diferencia se mantiene la responsabilidad objetiva, dado su carácter eminentemente formal y procedimental, y dada su descripción típica y atribución de responsabilidad tanto en el derecho nacional como comparado"(28).

A nuestro juicio, es un error sostener que, por el hecho de que una infracción sea imputada bajo un régimen de responsabilidad subjetiva ello implica per se que lo será a título de dolo o culpa, puesto que, si la descripción de la conducta en el tipo infraccional contiene un verbo nuclear que solo se asocia a la intención (verbi gratia distorsione) no puede perseguirse a título de culpa, sino que deberá imputarse la responsabilidad exclusivamente cuando la misma sea dolosa ${ }^{(29)}$.

Básicamente, lo que importará es el grado de subjetividad exigido para la configuración, lo que debe emerger de la descripción del tipo infraccional, esto es, la forma en que debe darse el elemento subjetivo para configurar el ilícito.

Otro problema que se presente ante este nuevo panorama legal es, si pese al cambio en la regulación de los regímenes de imputación en las infracciones aduaneras, y la pervivencia del régimen de responsabilidad objetiva

(26) Véase Andrés Varela, Exposición en la Cuarta Jornada Académica de Derecho Aduanero, inédito.

(27) Debe tenerse presente que el Código Aduanero de la República Oriental del Uruguay surge por iniciativa del Poder Ejecutivo, quien lo elabora y lo presenta como Proyecto de Ley ante el Poder Legislativo el cual prácticamente no le hizo modificación.

(28) Accesible en: Ministerio de Economía y Finanzas, Exposición de Motivos http://www.aduanas.gub.uy/innovaportal/file/10084/1/ exposicion_de_motivos.pdf

(29) Como es el caso de la infracción de defraudación de valor prevista en el numeral 1 del artículo 205 del CAROU, que dispone: "Artículo 205. Defraudación de valor.-

1. Configura la infracción aduanera de defraudación de valor toda declaración aduanera que distorsione el valor en aduana de las mercaderías en perjuicio de la renta fiscal.

2. La sanción será una multa igual al doble del importe de los tributos adeudados, sin perjuicio del pago de los mismos". 


\section{Andrés Varela}

para las Infracciones de Contravención y Diferencia ${ }^{(30)}$, es actualmente aplicable (o no) el criterios de benignidad o criterio de flexibilidad por parte de los Tribunales Judiciales, y ello, en relación a la única infracción cuya imputación se debe obtener en vía judicial, dado que la infracción de Contravención es procesable administrativamente por parte de la Dirección Nacional de Aduanas. Puesto que ha quedado no solo de manifiesto el régimen aplicable, sino también la voluntad del legislador de mantener el mismo.

Por otro lado, si bien oportunamente Ferrari Martino ha cuestionado el carácter de responsabilidad objetiva del artículo 287 de la Ley No. 13.318, que hoy ha sido recibido casi de forma literal en el inciso 3 del artículo 213 del CAROU ya transcripto, no surgen dudas en cuanto a la orientación que ha tomado el legislador, en tanto que se ha manifestado de manera expresa en el sentido conservar dicho régimen de responsabilidad objetiva para dos Infracciones (Diferencia y Contravención).

No obstante el cambio producido, y reconociendo que existen ciertas diferencias entre las infracciones de Diferencia y Contravención respecto de las infracciones aduaneras de Defraudación, Defraudación de valor, Desvío de exoneraciones y Contrabando, en cuanto a que aquellas infracciones refieren, en términos generales, a trasgresión de requisitos formales o a ciertos incumplimientos del deber de colaboración con el Organismo de Administración Aduanera, en el ejercicio de sus funciones de control, verificación, o fiscalización, aún ello, éstas diferencias no justifican un tratamiento diferenciado en cuanto al régimen responsabilidad del eventual infractor, por las mismas razones que hemos referido precedentemente.

Finalmente, la forma de conformación de los tipos infraccionales en la normativa aduanera uruguaya, puede llevar a sostener que, el elemento requerido en la mayoría de las infracciones - a excepción de la Contravención, y del alguna forma en que puede configurarse la infracción de Contrabando (en éste último caso, por la posibilidad que pueda configurarse el mismo, aun cuando no exista pérdida de renta fiscal si existe "...o en la violación de los requisitos esenciales para la importación o exportación definitivas de determinadas mercaderías que establezcan leyes y reglamentos especiales aún no aduaneros") - es la pérdida de renta fiscal.

Si bien no ha existido un mayor debate dogmático al respecto, se ha entendido que el bien jurídico tutelado en las infracciones aduaneras en Uruguay sería la renta fiscal, por ser el elemento requerido en todos los tipos infraccionales, a excepción de la Contravención. En tal sentido, el concepto renta fiscal abarca no solamente los tributos aduaneros, sino los no aduaneros, puesto que renta fiscal es comprensiva de ambos.

Como es sabido, las infracciones aduaneras suponen descripciones de diversas conductas que afectan de menor o mayor medida el quebrantamiento de la norma que regulan la actividad aduanera, pero puede suceder que el bien jurídico tutelado en las diversas infracciones sea diverso, y por ello, se deban adecuar las interpretaciones y aplicaciones al que resulte ser el bien jurídico tutelado de cada infracción.

Por ello entendemos que la determinación del bien jurídico tutelado se debe realizar a través de la interpretación de las normas que imponen sanciones en cada caso, lo que es de enorme trascendencia para su interpretación, respecto a lo cual debe avanzarse desde la dogmática aduanera uruguaya, para con ello dar soluciones a muchos de los problemas en torno al infraccional aduanero.

En tal sentido, enseña Altamirano que el concepto de bien jurídico protegido (o tutelado) asume un rol esencial en la interpretación de la ley y para la comprensión de la incriminación

(30) El numeral 3 del artículo 213 del CAROU determina:

““3. En las infracciones aduaneras de contravención y de diferencia no será admisible ninguna excusa fundada en la buena fe, en el error propio o ajeno o en la falta de intención de perjudicar o defraudar al Fisco." 


\begin{abstract}
Una necesidad imprescindible: Desterrar definitivamente el régimen de responsabilidad objetiva del infraccional aduanero An essential need: Banishing permanently strict liability from the customs infringement procedures
\end{abstract}

de un determinado comportamiento, desde una perspectiva de garantía política vinculado al plano del valor constitucional, y por otra parte, porque permite la interpretación teleológico del sistema infraccional, pues atiende al fin efectivo tutelado por la ley (Altamirano 2012, 666-667).

\section{Las presunciones en materia de imputación: un medio para equilibrar la dificultad de probar al Fisco, y que le permite probar al eventual imputado}

Como referíamos inicialmente, entendemos que, imperando un régimen de responsabilidad subjetivo dentro del cual se establezcan presunciones relativas en algunos supuesto especiales que puedan tener relación con la conducta intencional de los infractores, se puede conseguir equilibrar la dificultad probatoria del Fisco en materia de imputación de la conducta del infractor, sin violentar de modo alguno los derechos de los eventuales imputados, y ello, toda vez que tales presunciones cumplan ciertas condiciones requeridas a los efectos.

Así, la presunción es definida por D'ors como "el acto de aceptar la veracidad de un hecho por la evidencia de otro del que normalmente depende aquel hecho no probado"(31). Según Pugliese las presunciones se distinguen entre presunción simple y presunción legal $(1935,203)$. En la presunción simple (presunciones hominis) los hechos se vinculan mediante 01 proceso mental presidido por la lógica que elabora el juez, en la valoración de la prueba, en ocasión de la sentencia. En tanto la presunción legal, que son las establecidas por ley, es el legislador quien determina los hechos presumidos a partir de la determinación de un hecho que le sirve de base a aquel.

Ahora bien, según sea que la presunción legal pueda ser anuladas mediante el desarrollo de prueba en la cual se acredite en sentido contrario a la presunción, esto es, a la inexistencia del hecho presumido, o en su caso, no se admita prueba alguna contra la misma, las presunciones se clasifican en presunciones legales relativas (presunciones iuris tantum), en el primer caso, y presunciones legales absolutas (presunciones iuris et de iure), en el segundo.

Ello ha llevado a Navarrini y Asoley a caracterizar dicha distinción en función de la intensidad probatoria que presenta cada una de ellas (Navarrini y Asoley 2000, 97). La presunción constituye el resultado de técnicas legislativas en que se da por verdaderos hechos jurídicos de los cuales se desprenden determinadas consecuencias (Navarrini y Asoley 2000, 6).

Ahora bien, lo que caracteriza la presunción, es que el hecho presumido tiene un alto grado de probabilidad de existir en el mundo fenoménico, con prescindencia de la presunción. La probabilidad de existencia del hecho presumido se origina en la relación natural que existe entre el hecho presumido y el hecho que el legislador selecciona para que le sirva de base (Navarrini y Asoley 2000, 6). Así, la selección del hecho que sirve de base de la presunción se relaciona y correlaciona normalmente con aquel y según la experiencia lo acompaña. Por ello se ha dicho que la presunción crea una relación causal entre dos hechos que naturalmente están ligados ${ }^{(32)}$, por ser probables.

La función de la presunción es facilitar el establecimiento jurídico de un hecho cuando su prueba, dentro del campo del derecho, resulta difícil o improbable. Es aquí donde la tarea legislativa requiere de mayores

(31) Citado por Susana C. Navarrini y Rubén O. Asorey, Presunciones y ficciones en el derecho tributario. Doctrina. Legislación. Jurisprudencia, $2^{a}$ ed. (Buenos Aires: Depalma, 2000), 2, quienes toman la cita de J.L. Pérez de Ayala, "Las ficciones en el derecho tributario", en Memorias de la Asociación Española de Derecho Financiero (Madrid, 1968), 192.

(32) Ver Martín Oviedo, "Las ficciones en el derecho tributario", en Memorias de la Asociación Española de Derecho Financiero (Madrid, 1968), 384 y siguientes, citado por Susana C. Navarrini y Rubén O. Asorey, Presunciones y ficciones en el derecho tributario. Doctrina. Legislación. Jurisprudencia, $2^{\mathrm{a}}$ ed. (Buenos Aires: Depalma, 2000), 2. 


\section{Andrés Varela}

esfuerzos en lo que refiere a la selección de hechos que servirán de base a la presunción legal, puesto que, a través de la alegación y la prueba del hecho que sirve de base a la presunción legalmente establecidas es que se va a acceder a tener como cierto el hecho presumido, cuando no fuera probado en sentido contrario.

Es sabido que la ley pone de cargo de cada parte la prueba de sus afirmaciones, y en su caso, dicha parte soportará las consecuencias de la prueba de los hechos alegados. En tal sentido, en las presunciones relativas (iuris tantum) la prueba es condición para su vigencia, y por tanto, todos los medios de prueba pueden ser utilizados a tales efectos (Navarrini y Asoley 2000, 98).

En la prueba de las presunciones legales existe un fenómeno por el cual se produce el desplazamiento de la carga de la prueba para quien se ve favorecido con la presunción. Así, quien tiene que probar un hecho alegado, respecto del cual existe una presunción legal, puede probar el mismo, o puede probar el hecho que sirve de base al hecho presumido.

A nuestro entender, dicho fenómeno no se explica refiriendo al mismo como una inversión de la carga de la prueba, sino que, ello solo podría explicar la incidencia que tiene en la órbita del inculpado el resultado de la presunción. No obstante, dicho fenómeno produce un cambio en el objeto de la prueba para el favorecido por la presunción, en tanto que, quien encontrándose de principio con la carga de probar un determinado hecho necesario para su pretensión, se ve favorecido de una presunción legal que produce que no deba probar ese hecho si prueba un hecho distinto, y que le sirve de base a la presunción, por expresa determinación de la ley.

Pero, como decíamos, dicha presunción no hace cambiar la carga que originalmente tendría el denunciado (acusado o imputado) de contradecir, puesto que ésta se hubiera forzada si se hubiera producido prueba sobre el hecho objeto de prueba (el fundamental de la pretensión), en el mismo sentido que lo será, si quien se encuentra favorecido con la presunción logra probar el hecho base.
Todo ello con el aditamento que la prueba del hecho base de la presunción no otorga certeza plena sobre la existencia o inexistencia del hecho presumido, y por tanto, admite prueba en contrario, la cual no solamente puede surgir de la producida por el inculpado sino de toda la recabada en el proceso (regla de comunidad de la prueba), y que le fuera contraria a la presunción.

Recordándose además que el uso de las presunciones se presenta solamente en los casos en que del material probatorio del juicio, y en la etapa de valoración de la prueba, el juez no obtenga certeza plena de la ocurrencia o no de un determinado hecho que tenga relevancia para la pretensión de una de las partes, es ahí donde se recurre a las presunciones legales relativas.

Como ha señalado Fenech, el cambio en el objeto en los actos de prueba se producen cuando la utilización de los medios correspondientes, en lugar de tender a convencer al juzgador de la exactitud o veracidad de un hecho fundamental de la reclamación (por ejemplo: intención de defraudar), tiende a probar otro hecho (por ejemplo: existencia de dos o más juegos de libros para una misma contabilidad con distintos asientos) ligado con el primero por alguna vinculación jurídica o material (la existencia de una norma que dispone una presunción de intención defraudar cuando se comprueba la existencia de dos o más juegos de libros para una misma contabilidad con distintos asientos). Así se ha afirmado que la prueba se desplaza del thema probandi al thema probatum, esto es, del hecho que se tiene efectivamente interés en probar, al hecho que efectivamente se prueba( ${ }^{(33)}$.

(33) Véase Miguel Fenech, Derecho Procesal Tributario, Tomo III (Barcelona, 1951), 274, citado por Susana C. Navarrini y Rubén O. Asorey, Presunciones y ficciones en el derecho tributario. Doctrina. Legislación. Jurisprudencia, 99. 


\section{Una necesidad imprescindible: Desterrar definitivamente el régimen de responsabilidad objetiva del infraccional aduanero An essential need: Banishing permanently strict liability from the customs infringement procedures}

Ahora bien, a nuestro juicio, el verdadero problema probatorio para el Fisco, y que en definitiva se presenta como argumento justificante del régimen de responsabilidad objetiva, se encuentra en las infracciones que reprimen las defraudaciones en el sentido amplio del término, en las cuales, por su propia naturaleza, debe de reclamar el grado de intención (dolo), y las conductas que encierran tales hechos, los cuales son acompañados comúnmente con actos dirigidos a ocultar o simular su intención. Por tanto, en tales hipótesis infraccionales ciertamente resultan de difícil demostración la intención del actor de tales conductas.

Existe coincidencia en que las presunciones en materia infraccional aduanera, tienen por finalidad facilitar la actividad probatoria del Fisco. Si como venimos de ver, la justificación del régimen de responsabilidad objetiva se encontrara en la dificultad que resulta probar la intención en cierto tipo de infracciones, como son las que implican o requieren una conducta del individuo que se caracteriza por dirigirse a esconder la propia intención, en tales casos, pueden ser admitidas, bajo determinadas circunstancias, el establecimiento de ciertas presunciones que determinen la intención del infractor.

No obstante, y a nuestro juicio, la conducta culposa que fuera atrapada por una infracción, no podría ser favorecida por presunciones, puesto que esta conducta alcanzará a verificarse con la prueba de la divergencia entre la conducta requerida al agente por la normativa y la conducta asumida por aquel, esto es, mediante la concordancia o discordancia entre los deberes de cuidado que le son requeridos y sus resultados.

Si bien el régimen de presunciones puede suponer un esfuerzo probatorio mayor, posibilita al presunto infractor, alegar y probar en contra del hecho presumido, o del hecho base de la presunción. Así, el sindicado como infractor deberá, si pretende que dicha presunción no pese en su contra, dirigir su batería probatoria contra el hecho que sirve de base a la presunción, y en tal caso existiría contraprueba, mientras que si la actividad probatoria está dirigida a negar la afirmación presumida habrá prueba en contrario (Navarrini y Asorey 2000, 8).

Se ha advertido que se podría lesionar el principio de inocencia al presumir la culpabilidad del imputado, e invertir la carga de la prueba. Consideramos que las presunciones legales relativas por las cuales se presume el dolo de un sujeto, a través de una serie determinada de hechos no es contrario per se a la presunción de inocencia. No obstante, el problema no se resuelve por la simple oposición de dichas presunciones (presunción de inocencia vs. presunción legal simple de la existencia de intención, por ejemplo), sino por el contrario, por la correcta selección de hechos base que realice el legislador, que luego servirán de base legal para la presunción legal simple que se pretende estableces, esto es, el hecho presumido. En tal sentido, la determinación de los hechos base de la presunción se debe realizar a través de la selección y descripción de hechos que normalmente son presupuestos del hecho que se pretende presumir, si se prueba el hecho base determinada por el legislador en la norma.

Debe recordarse que la presunción es el resultado de un proceso lógico mediante el cual, de un hecho conocido cuya existencia es cierta, se infiere otro hecho cuya existencia es probable (Navarrini y Asorey 2000, 6). De tal suerte que, una incorrecta o difusa determinación de aquellos tendrá como consecuencia, ahora sí, la trasgresión del principio de inocencia.

En tal sentido, y como muestra de ello, se puede verificar una de las presunciones legales relativas determinadas en el Código Aduanero de la República Oriental del Uruguay, establecida en relación a las infracciones aduaneras de Defraudación y Defraudación de Valor, respecto de las cuales el CAROU estableció en el artículo 206, lo siguiente:

\footnotetext{
"Artículo 206) (Presunciones de defraudación).- Se presume la intención de defraudar respecto de las infracciones previstas en los artículos 204 y 205 de este Código, salvo prueba en contrario, cuando ocurra alguna de las siguientes circunstancias:
} 
Andrés Varela

(...)

E) Cuando se omitan o se establezcan incorrectamente los datos en los respectivos formularios o declaraciones, que para el control de la valoración, el origen o la clasificación establezca la Dirección Nacional de Aduanas".

Como puede comprobarse, del literal E resulta que, toda omisión o todo incorrecto establecimiento de datos que se realicen en los formularios o declaraciones que a efectos del control de la valoración, el origen o la calificación arancelaria haya establecido la Dirección Nacional de Aduanas, tendrá como consecuencia legal, tener por presumida la intención de defraudar, esto es, por verificado el dolo, claro está, salvo prueba en contrario, prueba que deberá producir el eventual infracto, para hacer desvanecer dicha presunción.

En tal caso, se rompe el criterio de selección del hecho base que se tiene como normalmente correlacionado con el hecho presumido (intención de defraudar), puesto que atrapa toda omisión o todo establecimiento de datos incorrectos, y ello, sin mayor esfuerzo puede verificarse que no es una conducta que pueda identificar de manera natural correlacionada con la intención de defraudar, puesto puede existir una omisión o un simple error sin que sea su correlato la intención de defraudar, todo lo cual produce que se vulnere la presunción de inocencia.

Obsérvese en sentido contrario, la previsión del Literal C del mismo artículo, que dispone: "C) Incumplimiento de la obligación de llevar o exhibir libros y documentación, o existencia de dos o más juegos de libros para una misma contabilidad con distintos asientos".

En dicha presunción de la intención de defraudar si se advierte una conexión probabilística entre el hecho base de la presunción (literal C) y la intención de defraudar, puesto que la verificación de un hecho de tal naturaleza tiene como probabilidad lógica y normalmente posible la intención de defraudar.

\section{Conclusiones}

Entendemos que la finalidad del proceso aduanero es determinar si los hechos que son denunciados, o descubiertos por los funcionarios aduaneros y puestos en conocimiento de la autoridad judicial, constituyen o no una infracción aduanera, y de serlo, imponer a su o sus responsables las sanciones establecidas legalmente como reproche a dicha conducta; multa, comisos, costas y costos del proceso, según corresponda a la infracción de que se trate; así como, en los casos que proceda, determinar el pago de los tributos correspondientes ${ }^{(34)}$.

El juzgamiento de las conductas infractoras a las disposiciones aduaneras debe contemplar de manera equilibrada los intereses del Estado en materia aduanera, principalmente fiscales, sin perjuicio de otros que tienen (y deben tener) mayor importancia (salud pública, medio ambiente, seguridad nacional, etcétera), y las garantías constitucionales de los ciudadanos.

El desconocimiento por el ordenamiento represivo aduanero del elemento subjetivo repugna a todo el sistema de valores de la sociedad, y ello se evidencia en las construcciones pretorianas de los tribunales judiciales que tienden a flexibilizar dicho régimen, incluso en contra de la propia norma positiva, como ha sido el caso de la jurisprudencia de Uruguay.

Por otra parte, si la aplicación de las sanciones por infracciones aduaneras se encuentra en manos de la propia Administración existe una inclinación natural de los funcionarios a proteger el interés de ésta, y ciertamente el resultado mecanicista será el esperado en interés del Fisco, en detrimento de los derechos de los ciudadanos.

Pero además, de tal suerte, que todo ello determina que las sanciones a las infracciones aduaneras, así concebidas y aplicadas, distorsionan la finalidad represiva de aquellas.

(34) En tal sentido, debe tenerse presente que todas las infracciones (salvo el Abandono) suponen la determinación de un responsable, la aplicación de sanciones y el pago de los tributos correspondientes. 


\section{Una necesidad imprescindible: Desterrar definitivamente el régimen de responsabilidad objetiva del infraccional aduanero An essential need: Banishing permanently strict liability from the customs infringement procedures}

En definitiva, se iguala donde no se debe, y lo se lo hace hacia abajo. Reprimiendo por el resultado y no por el grado de culpabilidad de la conducta. Siendo así todos responsables, tanto culpables como inocentes.

Ha dicho Altamirano, con absoluta claridad, que la culpabilidad no es un sentimiento ético, no es culpabilidad de conciencia; por el contrario, es culpabilidad jurídica, y siendo dificultoso el estudio del aspecto psicológico del comportamiento humano, a efectos de comprobar la existencia de culpabilidad exigida en la tipificación de la infracción tributaria (o aduanera) debe recurrirse a los datos o circunstancias objetivas que acompañan a la conducta típica aunque siempre con la cautela necesaria para evitar la penetración de cualquier forma de responsabilidad puramente objetiva, incompatible con el derecho fundamental de presunción de inocencia (Altamirano 2012, 685).

Finalmente, en la construcción de un repertorio infraccional por parte del Legislador, debe considerarse el bien jurídico tutelado, y cuáles son las conductas que afectan el mismo, como también deben considerarse mediante cuáles formas se desalentarán o reprimirán las conductas que afecten el ordenamiento aduanero, para poder realizar así una descripción precisa de las mismas. Asimismo, debe establecerse en ellas el grado de subjetividad requerida por el ordenamiento legal para la configuración de la infracción en cada caso.

Sólo en el caso de que la conducta requiera de dolo, y que el mismo fuera difícil de acreditar, por la naturaleza de la conducta descrita y sancionada, se deberá evaluar por el Legislador la utilización de presunciones respecto del elementos intención, determinando cuales son los hechos base que normalmente se pueden presentar ligados a aquel.

\section{Referencias bibliográficas}

Altamirano, Alejandro. 2012. Derecho Tributario. Teoría general. Buenos Aires: Marcial Pons.

Barreira, Enrique y Héctor Vidal Albarracín. 1989. La responsabilidad en las infracciones aduaneras. Revista $\mathrm{La}$ Ley, 1989-A, 925.
Camauër, Fernando. 2007. Infracciones Aduaneras. Su regulación en la parte General del Código Aduanero. En Estudios de Derecho Aduanero. Homenaje al Dr. Juan Patricio Cotter Moine, coord. Juan Patricio Cotter. Buenos Aires: Editorial Lexis Nexis.

Cotter, Juan. 2011. Las Infracciones Aduaneras. Consideraciones generales. En Estudios de Derecho Aduanero. Homenaje a los 30 años del Código Aduanero, coord. Juan Patricio Cotter. Buenos Aires: Editorial Lexis Nexis.

2014. Derecho Aduanero. $1^{\mathrm{a}} \mathrm{ed}$. Tomo II. Buenos Aires: Abeledo-Perrot.

De Jesús, Damásio. 2006. Imputación objetiva. Buenos Aires: Editorial DdeF.

De Palma del Teso, Ángel. 1996. El Principio de culpabilidad en el Derecho administrativo sancionador. Madrid: Editorial Tecnos.

Ferrari Martino, Rossana. 1997. La responsabilidad prevista en el art. 287 de la Ley $\mathrm{N}^{\circ} 13.318$ (Régimen represivo aduanero) ¿es objetiva? Revista de Comercio Exterior y Aduana 3 (enero).

García Vizcaino, Catalina. 2010. Derecho Tributario. Derecho tributario formal, procesal y penal. $4^{\mathrm{a}}$ ed. Buenos Aires: Abeledo-Perrot.

Guliani Fonrouge, Carlos. 1962. Derecho financiero. Volumen II. Editor Depalma.

Labandera, Pablo. 2012. La responsabilidad objetiva en materia de Derecho Aduanero: una rémora inaceptable. Tribuna del Abogado 178 (junio-julio).

2014. El Derecho Aduanero en Uruguay. En Derecho Aduanero. $1^{\text {a }} \mathrm{ed}$. Tomo III. Buenos Aires: Abeledo-Perrot. 


\section{Andrés Varela}

2016. Estudios sobre el Código Aduanero de la ROU. En Código Aduanero de la República Oriental del Uruguay. $1^{\text {a }}$ ed. Montevideo: Editorial La Ley Uruguay.

Mazz, Addy. 2001. La integración económica y la tributación. Montevideo: Fundación de Cultura Universitaria.

Navarrini, Susana y Rubén Asorey. 2000. Presunciones y ficciones en el derecho tributario. Doctrina. Legislación. Jurisprudencia. $2^{\mathrm{a}}$ ed. Buenos Aires: Depalma.

Nieto García, Alejandro. 2012. Derecho Administrativo Sancionador. $5^{\text {a }}$ ed. Madrid: Editorial Tecnos.
Pugliese, Mario. 1935. La prova nel processo tributario. Padova: CEDAM.

Quintero Olivares, Gonzalo. 1991. La autotutela, los límites al poder sancionador de la Administración Pública y los principios inspiradores del Derecho Penal. Revista de Administración Pública 126 (septiembre - diciembre).

Sluman, Juan. 2011. Pensando la culpa en las Infracciones Aduaneras. En Estudios de Derecho Aduanero. Homenaje a los 30 años del Código Aduanero, coord. Juan Patricio Cotter. Buenos Aires: Editorial Lexis Nexis.

Soler, Osvaldo. 2001. Derechos y Defensas del Contribuyente frente al Fisco. Buenos Aires: La Ley. 